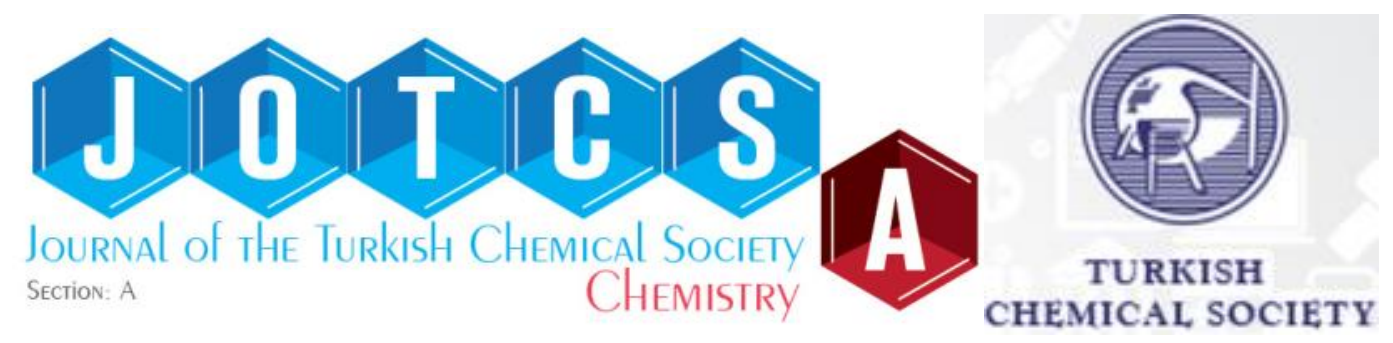

\title{
Investigation of Mineral Components and Antioxidant Properties of a Healthy Red Fruit: Cornelian Cherry (Cornus mas L.)
}

\author{
Merve Goksin Karaaslan ${ }^{1 *}$ (D), Nagihan M. Karaaslan² ${ }^{(D)}$, Burhan Ates ${ }^{1}$ \\ ${ }^{1 *}$ Inonu University, Faculty of Art and Science, Department of Chemistry, 44000, Malatya. \\ ${ }^{2}$ Munzur University, Faculty of Engineering, Department of Chemical Engineering, 62000, Tunceli.
}

Abstract: The mineral components of the foodstuff consumed by an individual are important in the growth and development of a human being. In recent years red fruits, because of their potential beneficial health effects, are getting attention of both consumers and manufacturers. One of the red fruits, Cornelian cherry (Cornus mas L.), was investigated in terms of both mineral components and antioxidant properties. The mineral components include calcium ( $\mathrm{Ca})$, iron (Fe), potassium (K), magnesium $(\mathrm{Mg})$, and zinc $(\mathrm{Zn})$ in this fruit were determined using flame atomic absorption spectrometry (FAAS). The antioxidant activity tests were applied to the extracts obtained using different solvents to examine the antioxidant properties of this fruit. Statistical analysis indicated that while the best results were obtained from acetone extracts, the lowest results were obtained from water extracts for all antioxidant activity tests $(p<0.05)$. The best average values for DPPH and ABTS radical scavenging capacity, reducing power, total phenolic content and total flavonoid content in acetone extracts were found to be $1053.72 \pm 38.12 \mathrm{mg} \mathrm{TEAC} / 100 \mathrm{~g}$ FW and $2907.34 \pm 152.05 \mathrm{mg}$ TEAC/100 g FW, $5894.99 \pm 251.05 \mathrm{mg} \mathrm{TEAC} / 100 \mathrm{~g} \mathrm{FW}, 2979.25 \pm 69.40 \mathrm{mg}$ GAE/100 g FW and $255.75 \pm 14.92 \mathrm{mg} \mathrm{QE} / 100 \mathrm{~g} \mathrm{FW}$, respectively.

Keywords: Antioxidant property; solvent type; mineral components; Cornelian cherry (Cornus mas L.)

Submitted: July 31, 2018. Accepted: November 13, 2018.

Cite this: Karaaslan MG, Karaaslan NM, Ates B. Investigation of Mineral Components and Antioxidant Properties of a Healthy Red Fruit: Cornelian Cherry (Cornus mas L.). JOTCSA. 2018; 5(3):1319-26.

DOI: http://dx.doi.org/10.18596/jotcsa.449593.

*Corresponding author. E-mail: mgkaraaslan@gmail.com. Tel: +90 4223773000 .

\section{INTRODUCTION}

Cornelian cherry, with a sour taste, generally grows in Asia and Europe (1). This fruit which is less common in comparison with other fruits grows in the temperate regions of Turkey. $A$ Cornus mas $L_{\text {., }}$ belonging into the family of Cornacea, is one of the few species consumed by people (2). In Turkey, this fruit can be eaten directly (dried or raw) or after treatment with some processes as jam, marmelade, pestil (a dried form of marmalade), paste, and sherbet (3).
Fruits that are antioxidant sources have many health benefits since they lower the risk of heart disease, cancer, and protect the body against free radicals $(4,5)$. Antioxidants help diminish oxidative damage to cells that can cause several serious illnesses. As mentioned in literature, one of the red fruits (Cornelian cherry) contains high amount of ascorbic acid, anthocyanin, phenolic compound, and antioxidant activity unlike many other fruits. Anthocyanin compounds which are abundant in this fruit have powerful antioxidant properties $(6,7)$ and they have anti-inflammatory effects (3). Phenolic compounds and especially flavonoids have an important role in the human diet and are known to be an important component in many medicinal plants (8). Cornelian cherry 
fruit has been used for the treatment of gastrointestinal disorders, diarrhea, and a number of diseases (9).

When the literature is examined thoroughly, the effect of solvent type on antioxidant activity has been disregarded in research regarding this fruit and in addition, few studies were reported dealing with its the mineral components. For this reason, the mineral components and antioxidant properties of cornelian cherry were examined in this study. The mineral components of cornelian cherry were determined by using FAAS. The antioxidant properties in different extracts (acetone, acetonitrile, ethanol, methanol and water) of this fruit were examined by using DPPH and $A B T S$ radical scavenging capacity, reducing power, total phenolic content, and total flavonoid content tests.

\section{MATERIAL AND METHOD}

\section{Apparatus}

To analyze $\mathrm{Ca}, \mathrm{Fe}, \mathrm{K}, \mathrm{Mg}$, and $\mathrm{Zn}$ elements, a Perkin Elmer Analyst 800 FAAS (Perkin Elmer, Inc., Shelton, CT, USA) was used. The measurements were carried out by using a single slot-burner head, air-acetylene flame and a lamp. The operation conditions for FAAS: $2 \mathrm{~L} \mathrm{~min}^{-1}$ flow of acetylene, $17.0 \mathrm{~L} \mathrm{~min}^{-1}$ flow of air were utilized for all element measurements. The slit width for $\mathrm{Ca}, \mathrm{K}, \mathrm{Mg}, \mathrm{Zn}$ was set to $0.7 \mathrm{~nm}$ and the slit width for Fe was adjusted to $0.2 \mathrm{~nm}$. The wavelength $(\mathrm{nm})$ for $\mathrm{Ca}, \mathrm{Fe}, \mathrm{K}, \mathrm{Mg}$, and $\mathrm{Zn}$ elements were set to 422.7 ; 248.3; 766.5; 285.2; and 213.9, respectively.

A microwave oven (Berghof, Germany) was used to dissolve the samples and standard reference materials. Before use, all glassware and reaction vessels were cleaned with $10 \% \mathrm{HNO}_{3}$ solution, then rinsed with tap water and deionized water. All antioxidant test measurements were conducted with a Shimadzu 1601 UV-Vis spectrophotometer (Tokyo, Japan).

\section{Reagents and standards}

All chemicals and solvents used were of analytically pure grade and purchased from Merck and Sigma-Aldrich. Ultrapure water (Milli-Q, Millipore $18.2 \mu \Omega \mathrm{cm}^{-1}$ resistivity) was utilized in the preparation of all solutions in this study. Standard solutions were prepared with different concentrations for the calibration graphics that are used in the determination of mineral components and applied for antioxidant activity tests.

The preparation of cornelian cherry samples Cornelian cherries (Cornus mas L.) were obtained from the local markets on the season in Malatya, Turkey. The samples were cleaned with tap water and ultrapure water, respectively, and then were homogenized with a domestic blender.

\section{Analytical procedure for mineral components}

Three identical fresh samples each weighing 1.0 grams were placed in Teflon vessels. $5 \mathrm{~mL}$ of $\mathrm{HNO}_{3} / 1 \mathrm{~mL} \mathrm{H} \mathrm{O}_{2}$ was added to the samples and dissolved in the microwave applying three steps; Step 1: $10 \mathrm{~min}$ to reach $150^{\circ} \mathrm{C}$ at $80 \mathrm{~W}$, Step 2: $10 \mathrm{~min}$ to reach $160{ }^{\circ} \mathrm{C}$ at $80 \mathrm{~W}$, Step 3: $20 \mathrm{~min}$ to reach $190{ }^{\circ} \mathrm{C}$ at $80 \mathrm{~W}$. After cooling to room temperature, the clear solutions were diluted to $30 \mathrm{~mL}$ with distilled water and analyzed by FAAS. NIST-1547 peach leaves standard reference material was used to determine the accuracy of the method. All procedures applied to dissolve the samples were also applied to the standard reference material. The element concentrations were calculated in terms of $\mathrm{mg}$ per $\mathrm{kg}$ of fresh weight ( $\left.\mathrm{mg} \mathrm{kg}^{-1} \mathrm{FW}\right)$.

\section{Analytical procedure for antioxidant activity tests}

Three identical fresh samples of about 5 grams of cornelian cherries were prepared for each solvent, they were extracted with solvents acidified to contain $0.1 \%$ hydrochloric acid solutions for antioxidant activity tests. $10 \mathrm{~mL}$ volumes of acetone, acetonitrile, ethanol, methanol, and water were added to the samples and they were extracted at room temperature for $1 \mathrm{~h}$. The obtained extracts were centrifuged (4000 rpm, $10 \mathrm{~min}$ ) and then filtered. The antioxidant activity tests such as 1,1-diphenyl-2picrylhydrazyl (DPPH) and 2,2'-azino-bis (3ethylbenzothiazoline-6-sulfonic acid) (ABTS) radical scavenging capacity, reducing power, total phenolic content, and total flavonoid content were applied to each clear supernatant. These tests were applied to sample extracts by slightly modifying the methods described in the literature. The experimental results were expressed in terms of $\mathrm{mg}$ per $100 \mathrm{~g}$ of fresh weight (mg/100 g FW).

\section{DPPH radical scavenging capacity}

The DPPH radical scavenging capacity test was carried out using the method applied by BrandWilliams et al. (1995) (10). The extracts were brought to a volume of $2.5 \mathrm{~mL}$ with DPPH solution and incubated at room temperature for $30 \mathrm{~min}$. After this incubation step, solutions' absorbance was determined at $517 \mathrm{~nm}$. Trolox was used as the standard and the results were expressed as Trolox equivalent ( $\mathrm{mg}$ TEAC/100 g) using the regression equation of the standard curve for Trolox $\left(y=0.123 x+3.4889 ; R^{2}=0.997\right)$.

\section{ABTS radical scavenging capacity}

The ABTS $\bullet+$ radical scavenging capacity test was applied to the sample extracts using the method reported by $\mathrm{Re}$ et al. (1999) (11). The extracts were brought to a volume of $2.5 \mathrm{~mL}$ with $\mathrm{ABTS} \bullet+$ stock solution and incubated for $30 \mathrm{~min}$ at room temperature, then solutions' absorbance was measured at $734 \mathrm{~nm}$. Trolox was used as the standard and the results were calculated from the 
regression equation of $(y=0.1481 x+4.0016$; $\left.R^{2}=0.9958\right)$ and expressed in terms of Trolox equivalent ( $\mathrm{mg}$ TEAC/100 g).

\section{Reducing power}

The reducing power test was performed using the method reported by Oyaizu (1988) (12). The extracts were mixed with $0.2 \mathrm{M}$ of phosphate buffer ( $\mathrm{pH}$ 6.6) and $1 \%$ potassium ferricyanide solution. These mixtures were incubated in a water bath $\left(50{ }^{\circ} \mathrm{C}, 20 \mathrm{~min}\right)$. After incubation, $10 \%$ of TCA was added and centrifuged (6000 $\mathrm{rpm}, 10 \mathrm{~min})$. Ultra-pure water and $0.1 \%$ iron (III) chloride were added to the supernatant. After $5 \mathrm{~min}$ incubation, colored solutions' absorbance was determined at $700 \mathrm{~nm}$. Trolox was used as the standard and the regression equation $\left(y=0.0003 x+0.0264 ; R^{2}=0.9947\right)$ was used to evaluate the results and they were expressed in terms of Trolox equivalent ( $\mathrm{mg}$ TEAC/100 g).

\section{Total phenolic content}

Total phenolic content of the extracts was determined using the Singleton and Rossi (1965) method (13). Folin-Ciocalteu reactant and 2\% sodium carbonate solution were added to the extracts. The mixtures' absorbance was measured at $755 \mathrm{~nm}$ after incubation $\left(25^{\circ} \mathrm{C}, 30\right.$ min). Gallic acid was used as the standard and results were calculated from the regression equation of $y=0.0022 x+0.0366 ; R^{2}=0.9926$ and expressed as gallic acid equivalent (mg GAE/100 g).

\section{Total flavonoid content}

Total flavonoid content of the extracts was determined using the method described by Zhishen et al. (1999) (14). 5\% sodium nitrite solution, $10 \%$ aluminum chloride, $1 \mathrm{M}$ sodium hydroxide were added to the extracts. The absorbances of the mixtures were detected at 510 $\mathrm{nm}$ after incubation ( $\left.25^{\circ} \mathrm{C}, 15 \mathrm{~min}\right)$. The amount of total flavonoid content was calculated through regression equation $\quad(y=0.001 x+0.0498$;
$\left.R^{2}=0.9988\right)$ and stated as quercetin equivalent (mg QE/100 g).

\section{Statistical analysis}

The one-way analysis of variance (ANOVA) and Tukey's multiple comparison tests were used to determinate the significance between the groups for antioxidant activity tests. Differences were considered statistically significant when $p<0.05$.

\section{RESULTS AND DISCUSSION}

The essential elements from dietary sources take an important place in the human diet and essential elements such as $\mathrm{Ca}, \mathrm{Fe}, \mathrm{K}, \mathrm{Mg}$, and $\mathrm{Zn}$ play a substantial role in metabolic mechanisms and these essential elements are abundant in fruits and vegetables (15). A few studies about the mineral components of Cornelian cherry (Cornus mas L.) have been reported in the literature. In this study, mineral components of this fruit were stated in terms of $\mathrm{mg} / \mathrm{kg}$; $425.92 \pm 42.14$ for $\mathrm{Ca}, 2.78 \pm 0.26$ for $\mathrm{Fe}$, $2090.82 \pm 233.27$ for $\mathrm{K}, 104.23 \pm 9.37$ for $\mathrm{Mg}$, and $1.34 \pm 0.14$ for $Z n$, respectively. The accuracy of these results was tested with NIST-1547 peach leaves standard reference material. The measured results were shown to be accurate since the results agreed by in $96 \%$ for $\mathrm{Ca}, 92 \%$ for $\mathrm{Fe}, 106 \%$ for $\mathrm{K}$, $93 \%$ for $\mathrm{Mg}$, and $94 \%$ for $\mathrm{Zn}$.

The interval values of an adult's dietary reference intakes (DRIs) of related elements per day (16) are presented in Table 1 . The reason why the values are given with a range is that the amounts of elements to be taken for males and females are different. All lower and upper limit values cover the amount of elements that must be taken for both an adult male and female per day. Moreover, this table also shows the percentage of the dietary reference intake values (DRI\%) taken for the body by assessing the results of our study in case an adult consumes $1 \mathrm{~kg}$ of Cornelian cherries per day.

Table 1. The interval values of an adult's DRIs and the percentage of an adult's DRI calculated by consuming $1 \mathrm{~kg}$ of cornelian cherries.

\begin{tabular}{lll}
\hline Element & Dietary Reference Intakes (DRIs) for adults & DRI\% \\
\hline $\mathrm{Ca}$ & $1000-1300 \mathrm{mg} / \mathrm{d}$ & $32.8-42.6$ \\
$\mathrm{Fe}$ & $8-18 \mathrm{mg} / \mathrm{d}$ & $15.4-34.75$ \\
$\mathrm{~K}$ & $4.5-4.7 \mathrm{~g} / \mathrm{d}$ & $44.5-46.4$ \\
$\mathrm{Mg}$ & $240-420 \mathrm{mg} / \mathrm{d}$ & $24.8-43.3$ \\
$\mathrm{Zn}$ & $8-11 \mathrm{mg} / \mathrm{d}$ & $12.2-16.8$ \\
\hline
\end{tabular}

Krosniack et al. (2010) investigated mineral contents of plum, pear, apple, and Cornelian cherry juices. They measured $\mathrm{Ca}, \mathrm{Fe}, \mathrm{K}$, and $\mathrm{Zn}$ content in the juice of the fruit in this study as $323.4 \pm 93.6 \mathrm{mg} / \mathrm{L}, 0.483 \pm 0.252 \mathrm{mg} / \mathrm{L}$, $1639 \pm 270 \mathrm{mg} / \mathrm{L}$, and $0.454 \pm 0.037 \mathrm{mg} / \mathrm{L}$, respectively. When they compared macro- micro elements of Cornelian cherry with other fruit juices, it was found that it is rich in terms of these elements. Therefore, since it is an important source of essential elements, it was suggested to be consumed by individuals who are particularly tolerant to dairy products (17). They were reported that the percentages of 
Recommended Daily Allowance (RDA) of Ca, $\mathrm{Fe}, \mathrm{K}$ and $\mathrm{Zn}$ in $1 \mathrm{~L}$ fruit juice was determined as $32.3 \%, 2.8 \%, 46.8 \%$ and $3.2 \%$, respectively. When the results of the present study which is expressed in Table 1 were compared with the results Krosniack et al., Ca and $\mathrm{K}$ values were found compatible, $\mathrm{Fe}$ and $\mathrm{Zn}$ values were ascertained as higher in daily intake of minerals. As a result, it is advisable to consume the fruit itself rather than the fruit juice if possible. Cetkovska et al. (2015) investigated basic nutritional properties of cornelian cherry cultivars. When the mineral composition of this fruit's nine cultivars was examined, the concentration intervals for the elements of this study were determined as $517 \pm 84-1164 \pm 142 \mathrm{mg} / \mathrm{kg}$ for $\mathrm{Ca}, 0.46 \pm 0.09$ $1.83 \pm 0.25 \mathrm{mg} / \mathrm{kg}$ for $\mathrm{Fe}, \quad 4225 \pm 394-$ $9729 \pm 122 \mathrm{mg} / \mathrm{kg}$ for $\mathrm{K}, 72 \pm 9-430 \pm 37 \mathrm{mg} / \mathrm{kg}$ for $\mathrm{Mg}, 0.48 \pm 0.13-4.42 \pm 0.24 \mathrm{mg} / \mathrm{kg}$ for $\mathrm{Zn}$. It was determined that the element composition changes depending on the cultivars of this fruit (18). When the present data was compared to the Cetkovska et al. (2015) study, though the $\mathrm{Ca}$ and $\mathrm{K}$ concentrations were lower, $\mathrm{Fe}$ concentration were higher than the specified interval they identified. As for $\mathrm{Mg}$ and $\mathrm{Zn}$ concentration, it was found in the stated interval cited by Cetkovska et al. (2015) study. These differences in the results in general may be caused by such factors as the cultivars, climate, temperature, soil type, and fruit maturity.

Since the antioxidant property of phenolic compounds are vital for the development of the human body, interest in vegetables and fruits containing these compounds is increasing day by day (19). It has been reported in the literature that the content of antioxidant in red fruits is high (20). The extraction process is important in the qualitative and quantitative analysis of phenolic compounds in various products such as fruits, vegetables, plants and flowers. Conventional solvent extraction techniques are generally used in the identification of antioxidant property of red fruits (20). In the current study, this technique was followed as usually proposed in the literature. When the studies in the literature were examined especially related with extraction parameters, it was determined that the experimental results were changed depending on solvent type (21). Therefore, solvent type was regarded as a significant parameter in the extraction process. The antioxidant properties of cornelian cherry were determined by antioxidant activity tests using acetone, acetonitrile, ethanol, methanol, and water extracts. When the statistical table were examined (Table 2), the lowest results were obtained in water extracts while the highest results were obtained in acetone extract in all antioxidant activity tests $(p<0.05)$. The average values obtained with acetone extract for DPPH and ABTS radical scavenging capacity, reducing power, total phenolic content and total flavonoid content were $1053.72 \pm 38.12 \mathrm{mg}$ TEAC/100 g FW and $2907.34 \pm 152.05 \mathrm{mg}$ TEAC/100 g FW, $5894.99 \pm 251.05 \mathrm{mg}$ TEAC/100 g FW, $2979.25 \pm 69.40 \mathrm{mg} \mathrm{GAE} / 100 \mathrm{~g} \mathrm{FW}$ and $255.75 \pm 14.92 \mathrm{mg} \mathrm{QE} / 100 \mathrm{~g}$ FW, respectively. The average values obtained with water extracts were $508.12 \pm 5.11 \mathrm{mg}$ TEAC/100 g FW for DPPH and $506.08 \pm 10.36 \mathrm{mg}$ TEAC/100 g FW for ABTS radical scavenging capacity, $920.65 \pm 68.03 \mathrm{mg}$ TEAC/100 g FW for reducing power, $439.85 \pm 34.57 \mathrm{mg} \mathrm{GAE} / 100 \mathrm{~g}$ FW for total phenolic content and $28.57 \pm 0.91$ $\mathrm{mg} \mathrm{QE} / 100 \mathrm{~g} \mathrm{FW}$ for total flavonoid content. DPPH and ABTS radical scavenging capacity, total phenolic content test results in order from highest to lowest for extractive solvents are as follows: acetone, methanol, ethanol, acetonitrile, water, respectively. The results for reducing power test were in decreasing order for extractive solvents are as follows; acetone, ethanol, methanol, acetonitrile, water. As for total flavonoid content, the result in decreasing order also for the extracts from acetone, acetonitrile, methanol, ethanol, and water.

Table 2. Antioxidant activity test results according to solvent type.

\begin{tabular}{|c|c|c|c|c|c|}
\hline Solvent & $\begin{array}{l}\text { DPPH } \\
(\mathrm{mg} \mathrm{TEAC} / 100 \mathrm{~g} \\
\mathrm{FW})\end{array}$ & $\begin{array}{l}\text { ABTS } \\
(\mathrm{mg} \text { TEAC/100 g } \\
\text { FW) }\end{array}$ & $\begin{array}{l}\text { Reducing } \\
\text { power } \\
(\mathrm{mg} \mathrm{TEAC} / 100 \mathrm{~g} \\
\mathrm{FW})\end{array}$ & $\begin{array}{l}\text { Total phenolic } \\
(\mathrm{mg} \mathrm{GAE} / 100 \mathrm{~g} \\
\text { FW) }\end{array}$ & $\begin{array}{l}\begin{array}{l}\text { Total } \\
\text { flavonoid } \\
\text { (mg QE/100 g } \\
\text { FW) }\end{array} \\
\end{array}$ \\
\hline Ace & $.12^{\mathrm{d}}$ & $2907.34 \pm 152.05$ & $\begin{array}{l}\text { d } \\
d\end{array}$ & $\operatorname{d}_{\mathrm{d}} 2979.25 \pm 69.40$ & $255.75 \pm 14.92$ \\
\hline $\begin{array}{l}\text { Ace } \\
\text { Etha }\end{array}$ & $\begin{array}{l}724 \\
922\end{array}$ & $\begin{array}{l}808.35 \pm 11.16^{b} \\
1567.68 \pm 53.27^{c}\end{array}$ & $\begin{array}{l}1207.73 \pm 74.23^{\mathrm{a}} \\
3531.91 \pm 172.71^{\mathrm{c}}\end{array}$ & $\begin{array}{l}721.86 \pm 28.72^{b} \\
2006.33 \pm 31.94^{c}\end{array}$ & $\begin{array}{l}126.20 \pm 0.70^{c} \\
76.01 \pm 2.61^{b}\end{array}$ \\
\hline Met & 933 & $63 \pm 91.30^{d}$ & ${ }_{b}^{2734.56 \pm 246.30}$ & $2110.29 \pm 84.00^{c}$ & $80.54 \pm 4.71^{b}$ \\
\hline Water & $508.12 \pm 5.11^{\mathrm{a}}$ & $506.08 \pm 10.36^{a}$ & $920.65 \pm 68.03^{a}$ & $439.85 \pm 34.57^{a}$ & $28.57 \pm 0.91^{\mathrm{a}}$ \\
\hline
\end{tabular}

Different letters in a column denote significant differences $(p<0.05)$

Results are average values \pm standard deviation, $n=3$

Moldovan et al. (2016) investigated antioxidant properties of cornelian cherry fruit.
They extracted samples with the acetone, and ABTS assay values of this fruit were found as 
$677.88 \pm 19.25 \mu \mathrm{mol}$ Trolox equivalents $/ 100 \mathrm{~g}$ fresh weight (22). In the current study, ABTS assay of Cornelian cherry fruit was tested with different extracts and the best result was obtained with acetone extract (2907.34 $152.05 \mathrm{mg}$ TEAC/100 g FW). In another study, antioxidant property of cornelian cherry which is grown in Turkey was investigated by using methanol as solvent. Tural and Koca found the total phenolic content to be in the interval of $2.81-5.79 \mathrm{mg} / \mathrm{g}$ and the average value was $4.37 \mathrm{mg} / \mathrm{g}(1)$. In our study, the average total phenolic content ( $2110.29 \pm 84.00 \mathrm{mg} \mathrm{GAE} / 100 \mathrm{~g} \mathrm{FW}$ ) in the experiment with methanolic extract was found to be significantly higher than those reported by Tural and Koca (2008). These all data demonstrated that the results in our study are consistent with the related literature. The variability of the results between these studies can be attributed to the extraction solvent, as well as the fruit-grown soil, vegetation, climatic conditions and fruit maturity. Hamid et al. (2011) examined antioxidant capacity and phytochemical properties of six cornelian cherry genotypes. Their findings for total phenolic content and total flavonoid content were in the intervals of $1097.19-2695.75 \mathrm{mg}$ GAE/100 $\mathrm{g}$ and 321.27-669 mg catechin/100 $\mathrm{g}$, respectively (5). In the present study, total phenolic content for different extracts were found in the range $439.85 \pm 34.57$ to $2979.25 \pm 69.40 \mathrm{mg} \mathrm{GAE} / 100 \mathrm{~g} \mathrm{FW}$ and total flavonoid content were found to range from $28.57 \pm 0.91$ to $255.75 \pm 14.92 \mathrm{mg} Q \mathrm{QE} / 100 \mathrm{~g}$ FW. It was observed that the results obtained from different genotypes of the same fruit change and as for our study, the results of the same fruit changed when using different extraction methods. Contrary to total phenolic content, when the total flavonoid content was compared, the average content of total flavonoid of the current study was found to be lower (5). In the study of Pyrkosz-Biardzka et al. (2014), antioxidant properties of methanolic crude extracts of Berberis vulgaris L., Cornus mas L. and Mahonia aquifolium Nutt were examined. They found total phenolic content to be $339.36 \pm 4.59 \mathrm{mg}$ GAE/100 g fresh mass and total flavonoid content as $63.86 \pm 3.04 \mathrm{mg}$ RE (rutin equivalent) $/ 100 \mathrm{~g}$ fresh mass for Cornus mas L. (23). When the related data were compared, quite high findings were obtained in the current study conducted with similar extracts. Gunduz et al. (2013) analyzed Cornelian cherry fruits at different stages of ripeness and reported that antioxidant activity of cornelian cherry fruits changes when its maturity level increases. In addition, they specified that the total phenolic content and antioxidant capacity results were observed to decrease as maturity increased for this fruit (2).
The findings of the study demonstrated that the mineral components and antioxidant activity of the Cornelian cherry were consistent with the studies presented in literature. As already reported in the literature slight differences can be attributed to several reasons; climatic factors, soil type, geographical and environmental conditions, degree of fruit ripeness, manipulation during fruit processing, and selection of analytical methods (18). Moreover, the differences in results for antioxidant property of this fruit can be caused by the solvent type. When the results of this study were evaluated according to the dielectric constant that is considered an indicator of the polarity, it was observed that the acetone solvent having the lowest dielectric constant value has the highest antioxidant activity data in all antioxidant tests. Because acetone, unlike other solvents, is capable of dissolving components of low to medium polar character. In addition, it was determined that water has a high dielectric constant value, which in turn has the lowest antioxidant activity data in all antioxidant tests. The results suggest that the choice of the solvent used in the antioxidant activity tests is important and should have the appropriate polarity to dissolve the desired compound.

\section{CONCLUSIONS}

In this study, the mineral components and antioxidant properties of Cornelian cherry (Cornus mas L.) were examined. For this purpose, mineral components including $\mathrm{Ca}$, $\mathrm{Fe}, \mathrm{K}, \mathrm{Mg}$ and $\mathrm{Zn}$ in this fruit were investigated by using FAAS. The data obtained shown that Cornelian cherry contain several essential elements and can be considered as a significant dietary mineral supplement. As for antioxidant properties, DPPH and ABTS radical scavenging capacity, reducing power, total phenolic content and total flavonoid content were examined in different extracts of this fruit. It was determined that experimental data changed depending on the solvent type. According to these results, the best results were obtained from acetone extracts while the lowest results were obtained from water extracts for all antioxidant capacity tests. Therefore, it should necessary to investigate the solvent type as one of the important extraction parameters when conducting similar studies. It was determined that this fruit might be used as a source of health in terms of mineral components and antioxidant properties.

\section{CONFLICT OF INTEREST}

The author declares no conflict of interest. 


\section{REFERENCES}

1. Tural S, Koca I, Physico-chemical and antioxidant properties of cornelian cherry fruits (Cornus mas L.) grown in Turkey. Scientia Horticulturae. 2008;116(4):362-6.

2. Gunduz K, Saracoglu O, Özgen M, Serce S, Antioxidant, physical and chemical characteristics of cornelian cherry fruits (Cornus mas L.) at different stages of ripeness. Acta Scientiarum Polonorum Hortorum Cultus. 2013;12(4):59-66.

3. Celik S, Bakırcı I, Şat IG, Physicochemical and organoleptic properties of yogurt with cornelian cherry paste. International Journal of Food Properties. 2006;9(3):401-8.

4. Shui G, Leong LP, Residue from star fruit as valuable source for functional food ingredients and antioxidant nutraceuticals. Food Chemistry. 2006;97(2):277-84.

5. Hamid $H$, Yousef $H$, Jafar $H$, Mohammad $A$, Antioxidant capacity and phytochemical properties of cornelian cherry (Cornus mas L.) genotypes in Iran. Scientia Horticulturae. 2011;129(3):459-63.

6. Prior $\mathrm{RL}$, Absorption and metabolism of anthocyanins: potential health effects. In: phytochemicals: mechanisms of action. Boca Raton, Fla., CRC Press, Inc, 2003.

7. Zafra-Stone $S$, Yasmin $T$, Bagchi $M$, Chatterjee A, Vinson JA, Bagchi D, Berry anthocyanins as novel antioxidants in human health and disease prevention. Molecular Nutrition \& Food Research. 2007;51(6):67583.

8. Cooper-Driver GA, Contribution of Jeffrey Harborne and co-workers to the study of anthocyanins. 2001;56(3):229-36.

9. Dinda B, Kyriakopoulos AM, Dinda $S$, Zoumpourlis V, Thomaidis NS, Velegraki A, Markopoulos C, Dinda M, Cornus mas L. (cornelian cherry), an important European and Asian traditional food and medicine: Ethnomedicine, phytochemistry and pharmacology for its commercial utilization in drug industry. Journal of Ethnopharmacology. 2016; 193:670-90.

10. Brand-Williams W, Cuvelier ME, Berset C, Use of a free radical method to evaluate antioxidant activity. Food Science and Technology-Lebensmittel-Wissenschaft \& Technolgie. $1995 ; 28(1): 25-30$.
11. Re R, Pellegrini N, Proteggente A, Pannala A, Yang M, Rice-Evans C, Antioxidant activity applying an improved ABTS radical cation decolorization assay. Free Radical Biology and Medicine. 1999;26 (9-10):1231-7.

12. Oyaizu M, Antioxidative activities of browning products of glucosamine actionated by organic solvent and thin layer chromatography. Nippon Shokuhin Kogyo Gakkaishi. 1988;35:771-5.

13. Singleton VL, Rossi JA, Colorimetry of total phenolics with phosphomolybdicphosphotungstic acid reagents. American Journal of Enology and Viticulture. $1965 ; 16: 144-58$.

14. Zhishen J, Mengcheng $T$, Jianming $W$, The determination of flavonoid content in mulberry and their scavenging effects on superoxide radicals. Food Chemistry. 1999;64(4):555-9.

156. Stacewicz-Sapuntzakis $M$, Bowen PE, Hussain EA, Damayanti-Wood BI, Farnsworth NR, Chemical composition and potential health effects of prunes: a functional food? Critical Reviews in Food Science and Nutrition. 2001;41(4):251-86.

16. Dietary Reference Intakes: The Essential Guide to Nutrient Requirements, The National Academies Press, Washington, D.C, http://www.nap.edu/catalog/11537.html.

17. Krosniak $M$, Gastoł $M$, Szałkowski $M$, Zagrodzki $P$, Derwisz $M$, Cornelian cherry (Cornus mas L.) juices as a source of minerals in human diet. Journal of Toxicology and Environmental Health, Part A. 2010;73(1718):1155-8.

18. Cetkovská J, Diviš $P$, Vespalcová $M$, Pořízka J, Řezníček V, Basic nutritional properties of cornelian cherry (Cornus mas L.) cultivars grown in the Czech Republic. Acta Alimentaria. 2015;44(3):357-364.

19. Shahidi F, Ambigaipalan P, Phenolics and polyphenolics in foods, beverages and spices: antioxidant activity and health effects-a review. Journal of Functional Foods. 2015;18:820-897.

20. Hidalgo G-I, Almajano MP, Red Fruits: Extraction of antioxidants, phenolic content, and radical scavenging determination: a review. Antioxidants. 2017;6(1):1-27.

21. Boulekbache-Makhlouf $L$, Medouni $L$, Medouni-Adrar S, Arkoub L, Madani K, Effect of solvents extraction on phenolic content and antioxidant activity of the byproduct of 
eggplant. Industrial crops and products. 2013;49:668-74.

22. Moldovan B, Filip A, Clichici S, Suharoschi R, Bolfa P, David L, Antioxidant activity of cornelian cherry (Cornus mas L.) fruits extract and the in vivo evaluation of its antiinflammatory effects. Journal of Functional Foods, 2016;26:77-87.
23. Pyrkosz-Biardzka K, Kucharska AZ, SokółŁętowska A, Strugała P, Gabrielska Janina, A comprehensive study on antioxidant properties of crude extracts from fruits of Berberis vulgaris L., Cornus mas L. and Mahonia aquifolium Nutt. Polish Journal of Food and Nutrition Sciences. 2014;64(2):919. 
Karaaslan MG, Karaaslan NM, Ates B. JOTCSA. 2018; 5(3):1319-1326. RESEARCH ARTICLE 